\title{
Appadurai, Arjun (2007), El rechazo de las minorías. Ensayo sobre la geografía de la furia, Alberto E. Álvarez y Araceli Maira (Tr.), Barcelona: Tusquest, Colección Ensayo, núm. 71.
}

Violencia y cultura en un mundo global

Introducción

A rjun Appadurai presenta El rechazo de las minorías. Ensayo sobre la geografía de la furia como la segunda entrega de un proyecto de largo alcance cuya primera aportación fue La modernidad desbordada: dimensiones culturales de la globalización (1996). Las reflexiones presentadas en ese libro recibieron críticas por presentar una visión positiva de la globalización y francamente optimista de la función de los paisajes mediático e ideológico para fomentar y fortalecer los entrecruces culturales. No obstante, poco se comentó sobre la conclusión del autor respecto a un panorama poco alentador para las comunidades de convivencia local cuyo contexto se había vuelto más complicado con la globalización. Al tiempo que mantiene una tesis desarrollada a lo largo de su trabajo: la cultura no es algo esencial sino un conjunto de factores que se significan en algún espacio local y, por lo tanto, algo que no se homogeneizará en el marco de la globalización; "El rechazo de las minorías" atiende de manera directa al complejo panorama que se presenta a las comunidades en el contexto de la globalización y a la reconfiguración de la hegemonía global. A pesar de que el título evoca tópicos sobre los cuales se tiene una valoración negativa y que sus hipótesis pueden ser cuestionadas, esta entrega concluye con una visión utópica permeada por la esperanza.

En 192 páginas que componen seis capítulos Appadurai nos invita a reflexionar sobre por qué en el contexto de la globalización siguen ocurriendo etnocidios, y a comprender cómo se ha reconfigurado la hegemonía mundial después de los ataques terroristas del 11 de septiembre de 2001 a los Estados Unidos de Norteamérica. El problema identificado es, precisamente, que las últimas dos décadas; dominadas por la doxa (Bourdieu, 1991) de mercados abiertos, expansión de las instituciones democráticas y de las tecnologías de la información como instrumentos para incrementar la libertad, la transparencia y el buen gobierno, incluso para mitigar la desigualdad; también ha sido el período de violencia a gran escala en diferentes sociedades y regímenes políticos, aun aquellos que se consideran democráticos y arraigados en valores liberales. La pregunta a responder es no solo el porqué la violencia resulta productiva en el plano social, sino por qué esa violencia se dirige contra grupos definidos como minorías. 


\section{El contenido de la obra}

En el capítulo l. "Del etnocidio al ideocidio", presenta los fundamentos teóricos de su reflexión. Ahí se encuentra un interesante entrecruce de las reflexiones de la filosofía política sobre la unidad en la vida política en Occidente —el individuo - y la consecución de mayorías, con las reflexiones antropológicas para el análisis de los rituales sociales ligados a la "pureza" y la "impureza", a las que se suman las propuestas sociológicas del estudio de la formación del Estado nación. Sobre este punto, Appadurai ratifica un argumento presentado por Gellner (1989) respecto que cada Estado crea sus propios mitos y rituales para legitimar a una etnia, que por lo general es la mayoritaria, y hace pasar sus propios valores, tradiciones y costumbres como la esencia del genio de la "etnia nacional".

El modelo interpretativo se resume en que las ideologías de las "mayorías numéricas" y el "nacionalismo racista" se encuentran en el corazón mismo del liberalismo. La violencia se explica por lo que denomina "angustia de lo incompleto". Es decir, "las mayorías numéricas pueden convertirse en predatorias y etnocidas de los números pequeños precisamente cuando algunas minorías - y sus números pequeñosrecuerdan a las mayorías la pequeña brecha que media entre su condición de mayoría y el horizonte de un todo nacional impoluto, de una etnia nacional pura y sin tacha" (pp. 22). En este modelo la globalización agrega el ingrediente de la rapidez y la intensidad con la que las personas, elementos materiales e ideológicos, circulan a través de fronteras nacionales. Eso crea un nuevo orden de incertidumbre en la vida social respecto a la identidad social, los valores, la tradición y la dignidad de los "otros": las minorías. Esto al tiempo que producen formas locales o regionales de fundamentalismo cultural, o la autoidentificación del "nosotros"; pero también exacerba las condiciones de violencia a gran escala debido a que genera una potencial colisión entre la lógica de la incertidumbre y la lógica de lo incompleto.
En el segundo acápite "La civilización de los choques", ironiza y va más allá de la propuesta de Samuel Huntington (2005), para señalar que debemos pensar "en nosotros mismos como seres que viven en una civilización mundial de choques" (pp. 32). Observa que la rápida difusión del término "terrorismo" ha tenido dos consecuencias: 1. se ha desdibujado la línea entre las guerras de la nación y las guerras en la nación; y 2. habrá que tomarse en serio la idea de una guerra sin autor, o mejor dicho, la posibilidad de que cualquier Estado nación aplique tal término — terrorista- a sus propios disidentes, activistas anti Estado y minorías para justificar, con ello, su exterminio. Atiende entonces a la reconfiguración de la hegemonía mundial luego de los ataques del ll de septiembre.

Esta reconfiguración es presentada bajo la forma de una "trinidad". Por un lado Estados Unidos y sus aliados como defensores de la civilización; por otra parte, el enemigo que fue denominado "red terrorista global"; y las otras redes que Appadurai denomina "globalización desde abajo". En este capítulo recurre a la propuesta de la "celularidad" de la "sociedad red" desarrollada por Manuel Castells (1999), para concluir que a esa "trinidad" subyace una guerra entre dos tipos de sistema de alcance global. El primero que denomina "vertebrado", el segundo "celular". El primero corresponde a los Estados nación, una estructura jerárquica que funciona gracias a "un vasto y creciente cuerpo de protocolos, instituciones, tratados y acuerdos" (pp. 41); y el segundo es un sistema de redes "conectadas, pero no dirigidas verticalmente; coordinadas, pero notablemente independientes; capaces de dar respuestas, sin contar con una estructura centralizada de comunicación; borrosas en sus principales líneas de organización, pero con la claridad del día en sus estrategias y efectos" (pp. 44).

Appadurai sostiene que la guerra entre esos sistemas induce a una mayor incertidumbre social porque borra sistemáticamente los límites entre los espacios y tiempos de la guerra y la paz. Con ello, las 
normas excepcionales de la violencia y la transgresión se convierten en pilar de la vida cotidiana. Concluye que también se trata de una agresión epistemológica "porque desestabiliza nuestros dos presupuestos más preciados: que la paz es el indicador natural del orden social y que el Estado-nación es el garante y el receptáculo natural de ese orden" (pp. 50).

En el capítulo "Globalización y violencia", además de retornar a los argumentos antropológicos planteados en su modelo inicial, desarrolla la hipótesis de mayor interés de este trabajo: "la globalización de la violencia contra las minorías representa una profunda angustia en relación con el proyecto nacional y su propia relación ambigua con la globalización" (pp. 64). En el mundo global encontramos el temor social a la exclusión, soberanías nacionales cuestionadas y la ampliación de la brecha entre ricos y pobres. Este último factor es el causante de las formas de violencia social cotidiana contra la mujer, el trabajo infantil o los desplazamientos forzados, por ejemplo- y un contexto propicio para el tráfico global de armas, tanto para la "protección" como para delinquir. En ese contexto se desarrollan ejércitos, grupos paramilitares, zonas de seguridad, expertos en protección y guardaespaldas "privados", acompañado por la propagación en los medios de imágenes de inseguridad, guerras y etnocidios.

Es decir, la lógica de la globalización pone a los Estados nación en una cadena en la cual sus ciudadanos viven una situación minoritaria y marginal — real o imaginada - en un mundo de unos pocos mega Estados, bloques comerciales, de flujos económicos ingobernables y de soberanías en peligro; cuya evidencia cotidiana la encuentra el ciudadano a través de los medios que transmiten imágenes de violencia e inseguridad. La angustia que muchos Estados y sus ciudadanos padecen por esa situación se desplaza a las minorías, ya que son una vergüenza para toda la imagen de pureza nacional y de justicia pública patrocinada por los Estados. Así las minorías son los chivos expiatorios para una situación en la cual son solicitantes desvalidos de los subsidios estatales o son una de las causas de la disminución de recursos nacionales muy disputados. En ese sentido, la violencia global es un intento de exorcizar lo nuevo, lo emergente, lo incierto, que se materializa a través de las minorías.

"El temor a los números pequeños" es el cuarto capítulo donde Appadurai define como predatorias a "aquellas identidades cuyas construcciones sociales y movilización requieren la extinción de otras categorías sociales próximas, definidas como una amenaza para la existencia misma de determinado grupo definido como nosotros" (pp. 69). Estas identidades cuentan con una ideología "mayoritarista" que está invariablemente relacionada con las ideas de la singularidad y el carácter completo propio de la "etnia nacional", intentan vincularse exclusiva o exhaustivamente con la identidad de la nación y movilizan con éxito la "angustia de lo incompleto".

Siguiendo una argumentación que recuerda los postulados de la poliarquía de Robert Dahl (1993) señala que el concepto de minoría se vincula con las opiniones discrepantes expresadas en contextos deliberativos o legislativos dentro de un marco democrático. Nos recuerda entonces que la idea de minoría "no es una noción ética o cultural", sino "procedimental". Además de enumerar una sería de elementos históricos que hacen posible la identificación de minorías y la imaginación de la pureza nacional; observa que la violencia se genera en aquellos Estados donde la cuestión de los números se identifica con una cuestión de cualidades; en donde el valor normativo de las minorías se desplaza a un valor sustantivo o a identidades - como las étnicas o religiosas - que son permanentes. Aquí es donde los diferentes procesos de la globalización entran en juego, pues coadyuvan a exacerbar la incertidumbre social y a que los grupos con ideologías mayoritaristas trasladen sus angustias a las minorías para identificarlas con el fantasma de la conspiración, el espía, el traidor, el disidente, el revolucionario o, en fechas recientes, con la célula terrorista. 
En el capítulo "Nuestros terroristas, nosotros mismos", Appadurai retoma su argumentación sobre la guerra entre los sistemas celulares y vertebrados para integrarla al modelo de la angustia de lo incompleto. Señala que una vez que se logra la metonimia anterior; ciudadanos y sistemas vertebrados han creado la mezcla letal que produce la lógica de la purificación étnica. Proceso que inicia con una desmesurada desconfianza sobre la identidad "real" de los "otros". Esa incertidumbre se incrementa hasta que un grupo empiece a sentir que la misma existencia del otro grupo conlleva un peligro para su propia supervivencia. La violencia a gran escala podría considerarse una respuesta compleja ante niveles intolerables de incertidumbre sobre la identidad de los grupos —el propio y los otros.

Presenta entonces sus argumentos en torno a la "geografía de la furia", que se guía por el propósito de determinar cómo y en qué condiciones un mayoritarismo liberal puede volverse intolerante y potencialmente genocida. En primer lugar, esa geografía se vincula en el mundo actual al imaginario de la "red terrorista global", porque el terrorista es el adalid de la transgresión social: desdibuja el espacio militar y civil, violenta las soberanías y las fronteras, une en una misma persona al soldado y al espía que se hace pasar por un "ciudadano" común y corriente. Es decir, el terrorismo opera a través del mecanismo de la incertidumbre, lo cual produce una nueva geografía política.

Se trata de la transformación de varias geografías locales y regionales como consecuencia de una geografía más amplia de indignación nacional y furia global contra el terror, que legitima a los Estados nación a la hora de emprender acciones para el fortalecimiento militar, aumento de controles internos, campañas nacionales para eliminar el tratamiento especial a inmigrados o restringir el acceso a servicios prestados por el Estado a los no nacionales y presentar a las mayorías nacionales como vulneradas y ofendidas por las minorías y en especial por aquellas provenientes del mundo musulmán. Ocurre entonces un proceso simultáneo; las naciones democráticas crean minorías interiores, mientras que algunos integrantes de tales minorías prefieren identificarse con el mundo celular global, antes que con el aislante mundo de las minorías nacionales.

La "geografía de la furia" es por lo tanto un "mapa mental" del mundo global en el que se superponen gradualmente la guerra, la seguridad, el crimen y el terror; sobre las líneas del comercio, el transporte, el trabajo y el consumo. Concluye con dos argumentos: 1. que las regiones, naciones y ciudades, "pueden producir replicas fractales complejas de enfrentamientos mayores" - de las formas políticas celulares y vertebradas-; 2. que existe una relación "renovada entre la incertidumbre de la vida cotidiana y la inseguridad de los asuntos del Estado" (pp. 127).

El sexto y último acápite, "La globalización de las bases en la era del ideocidio", retoma la crítica al modelo del "choque de civilizaciones" que califica de "primordialismo con una base macrogeográfica", es decir, un isomorfismo entre historia, cultura, identidades étnicas y territorio, del cual a final de cuentas solo deja la "geografía". Lo que ocurre, según Appadurai, es un complejo proceso cultural en el que se combinan la angustia de lo incompleto, la lógica de la incertidumbre y el temor a los números pequeños. Esto cierra su "bucle explicativo". Esa convergencia genera el "ideocidio", es decir, fenómeno en el cual ideologías o civilizaciones son consideradas como perniciosas y objetos apropiados para una "muerte social". Aquí ocurre una nueva metonimia en el mapa mental de la geografía de la furia en la cual los valores, ideologías y formas de vida de la civilización musulmana se identifican con la "red terrorista mundial". Así los oponentes morales de la civilización —occidentalse identifican en el mundo occidental con minorías locales, lo cual genera una doble lógica: la globalización de oponentes morales internos y la localización de enemigos morales alejados. 
Sin embargo, no todo es violencia y destrucción. En la parte más utópica de su planteamiento, Appadurai recurre - sin citar- a las tesis durkheimnianas de la formación de solidaridades como hechos morales para argumentar la existencia de una "globalización desde abajo". Se trata de un mundo celular, cuyas partes se multiplican por "asociación” y según las oportunidades que emergen en el mundo global para realizar "política a distancia". Esta forma de hacer política se sustenta en valores cosmopolitas y progresistas que crean una tercera esfera más allá del Estado y del mercado. Pero que a la vez que se sustentan en el respeto a la ley y los derechos universales, atienden de manera sensible problemas locales. En sus aspiraciones estas formas celulares de asociación son democráticas tanto en su forma como en su télos. Su acción se dirige a establecer ciertos protocolos y principios para un autogobierno, la construcción de capacidades y el apoyo a los más desfavorecidos por la globalización para que puedan ser los arquitectos directos de sus mundos políticos locales.

Appadurai concluye que en la guerra entre organismos celulares y vertebrados, la futura crisis de los Estado nación podría no encontrarse en el enemigo identificado como "red terrorista global", sino en estas redes globales de apoyo transnacional, en la globalización de las bases. Aunado a ello considera que son la clave para contrarrestar la tendencia al etnocidio $\mathrm{y}$ al ideocidio.

\section{Invitación a la lectura}

A una década de los atentados a Estados Unidos de Norteamérica, y cuatro de publicación en español de El rechazo a las minorías, esta obra resulta sumamente vigente por el diagnóstico de Appadurai sobre las formas en las que se está reconfigurando la hegemonía mundial, los agentes que se encuentran en disputa y cómo esas transformaciones devienen en el mapa mental que él denomina una "geografía de la furia". Sin duda alguna, será una de las obras de referencia que se suman a explicarnos una de las problemáticas más acuciantes de la modernidad globalizada y que ha ocupado a las mentes más connotadas de las ciencias sociales contemporáneas.

Los interesados en comprender por qué en la modernidad emerge la violencia y por qué el modelo de sociedad global todavía merece el adjetivo de "riesgo" encontrarán en el ensayo de Appadurai una explicación de carácter cultural, con el gran acierto de recordarnos que las culturas son "mapas mentales"; al tiempo que no recurre a los argumentos de la sobre determinación estructural ni a las explicaciones de carácter individualista. Sumado a lo anterior, nos ofrece una visión novedosa de la recomposición de la hegemonía global, al tiempo que descentra la discusión sobre el terrorismo, para llamar nuestra atención respecto a que la "sociedad de riesgo" en la que vivimos es tal porque la complejidad propia del actual contexto globalizado crea altos niveles de incertidumbre social.

No obstante lo señalado, en este libro encuentro dos aspectos sobre los cuales considero valdría la pena reflexionar más acuciosamente y quizá valdría la pena abrir nuevas sendas de investigación. El primero tiene que ver con su acercamiento a la "globalización desde abajo". Si bien es cierto que formalmente su estructura y susfines, como la equidad, la transparencia ylainclusión, son bastiones para la democratización, no encontramos nada que documente que el comportamiento empírico de los grupos locales, que se suman a las redes globales, sea en realidad democrático. Antes bien, las hipótesis que podemos extraer son que reproducen viejas prácticas poco democráticas, pero que resultan provechosas en contextos locales. Valdría la pena indagar cómo se resuelven esas tensiones en los nuevos mapas mentales. Una segunda observación es de carácter metodológica. Desde "La modernidad desbordada" se enfatiza en la importancia de los paisajes, y en "El rechazo a las minorías" incluso se pone el paisaje mediático como el principal detonante de los mecanismos que desatan la violencia etnocida; no obstante, a más de enumerarlos 
—paisaje financiero, paisaje mediático, paisaje ideológico, paisaje étnico, paisaje tecnológico-falta el desarrollo de herramientas que permitan documentar etnográficamente las articulaciones entre ellos.

Con reserva de que ese "proyecto de largo alcance" nos ofrezca nuevos productos en los que podamos encontrar pistas para subsanar esos vacíos, sin duda alguna estamos ante una innovadora propuesta para explicar el papel que los agentes celulares toman para evitar que las normas $\mathrm{y}$ valores de un marco formalmente democrático, que resultan loables, devengan en mecanismos culturales que motiven comportamientos etnocidas.

\section{Bibliografía}

Appadurai, Arjun (1996), Modernity at large. Cultural dimensions of globalization, Minneapolis: University of Minnesota Press.
Bourdieu, Pierre (1991), El sentido Práctico, Madrid: Taurus, Colección Humanidades.

Castells, Manuel (1999), La era de la información. Economía sociedad y Cultura, México D. F.: Siglo XXI.

Robert A. Dahl (1993), La poliarquía, México: REI.

Gellner, Ernest (1989), Cultura, identidad y política: El nacionalismo y los nuevos cambios sociales, Barcelona: Gedisa.

Huntington, Samuel (2005), El choque de las civilizaciones y la reconfiguración del orden mundial, México: Paidós.

Luis Rodríguez Castillo Universidad Nacional Autónoma de México PROIMMSE-IIA lurodri@unam.mx 